\title{
Example Construction as a Devise to Reveal Awareness of Calculus Integration
}

\author{
Shafia Abdul Rahman ${ }^{1 *}$ \\ ${ }^{1}$ Abu Dhabi University, UNITED ARAB EMIRATES \\ *CORRESPONDENCE: $\$ shafia24@yahoo.co.uk

\begin{abstract}
Meaningful mathematics learning requires creating opportunities for learners to make use of their awareness to contact important mathematical structures. Four first year undergraduates studying engineering, mathematics and education were invited to construct examples meeting specified constraints in order to investigate their awareness of Integration. Findings suggest that the examples they constructed reflected the nature of their awareness of the topic and aspects of the topic that dominated the students' attention.
\end{abstract}

Keywords: dimensions of variation, example construction, integration, mathematical awareness

\section{INTRODUCTION}

Calculus is a central branch of mathematics, which is built largely on two major complementary ideas: differentiation and integration. Differential calculus studies rates of change, which are usually illustrated by the slope of a line or of a curve at a point. Integral calculus, on the other hand, studies the accumulation of quantities, such as areas under a curve, linear distance travelled, or volume displaced. The relationship of the two concepts, differentiation and integration, is made precise by The Fundamental Theorem of Calculus.

Research that looked into learners' difficulties in understanding concepts in calculus have focused mainly on learners' inabilities to think flexibly and to reflect on what they have done. Concern has been raised about the rote, manipulative learning that takes place in calculus courses (Cipra, 1988; Steen, 1988; White, 1990). Learner difficulties in many areas of calculus such as rate of change (Orton, 1983), limit (Cornu, 1992; Tall \& Vinner, 1981), tangent (Vinner, 1981) and function (Dreyfus \& Eisenberg, 1982; Tall, 1993; Vinner \& Dreyfus, 1989) have been well documented.

Tall (1993) identifies a number of fundamental difficulties associated with calculus learning including language confusions associated with the limit concept, restricted mental images of functions and learner preference for procedural methods rather than conceptual knowledge. To overcome the conflict, he suggests that learners must "reconcile the old and the new [knowledge] by re-constructing a new coherent knowledge structure" rather than "keep[ing] the conflicting elements in separate compartments and never let[ting] them be brought simultaneously to the conscious mind" (p. 3). Dreyfus and Eisenberg (1991) voice similar concern in relation to images and representations when they say learners tend to "reduce the mathematics of calculus to a collection of algebraic algorithms, while avoiding graphics as well as geometrical images" (p. 25). Swinyard (2011) studied the evolution of the students' definition, and concluded that students can reinvent a coherent definition of limit. He showed how students reason about and reinvent a formal definition of limit capturing the intended meaning of the conventional definition.

Article History: Received 11 September $2018 \bullet$ Revised 24 October $2018 \bullet$ Accepted 2 December 2018

(C) 2019 by the authors; licensee Modestum Ltd., UK. Open Access terms of the Creative Commons Attribution 4.0 International License (http://creativecommons.org/licenses/by/4.0/) apply. The license permits unrestricted use, distribution, and reproduction in any medium, on the condition that users give exact credit to the original author(s) and the source, provide a link to the Creative Commons license, and indicate if they made any changes. 
Both integration and differentiation have wide applications in physics, chemistry, engineering and technology. A number of researchers have considered the topic of integration (e. g. Bezuidenhout \& Oliver, 2000; Czarnocha et al., 2001; González-Martín et al (2014); Hong \& Thomas, 1997; Huang, 2012; Jones, 2013; Orton, 1983; Rasslan \& Tall, 2002; Sealey, 2006; Tsamir, 2007). They found that, in general, learners do not have a comprehensive view of integration and that learners could not cope well with slightly modified situations.

What is salutary in these reports are the authors' claims about learners' lack of flexibility and knowledge of underlying principles. They point to the fact that learners may have procedural knowledge of integration in terms of techniques, without adequate conceptual knowledge of the underlying principles. The studies appear to seek to explore awareness by observing behavior alone. However, as the anthropological adage "absence of evidence is not evidence of absence" suggests, just because learners do not say something (about a concept), it does not follow that the concept is not there. It merely reflects the fact that there has been no reason to express it. I suggest that all we can say was that it did not come to the surface sufficiently strongly to be manifested in behavior. Learners may mis-remember techniques and may not be able to check or reconstruct a technique when needed. This may explain what is happening when learners do not cope with unfamiliar situations or tasks. Trying to memorise procedures leaves learner vulnerable to mis-remembering or forgetting. Particularly in the case of integration, the integral sign links to many different methods of integration depending on the nature of the function being integrated and is involved in many different applications. This may explain why learners appear confused and resort to exercising their memory rather than dealing with the situation creatively and constructively.

Example construction tasks have been used by a number of researchers to study learners understanding of mathematical topics (e. g. Dahlberg \& Housman, 1997; Hazzan \& Zazkis, 1999; Weber \& Alcock, 2004). While pedagogical aspects of constructing example have been broadly discussed (e.g. Abdul Rahman, 2005; Leinhardt, 1993; Watson \& Mason, 2005; Zazkis \& Leikin, 2008; Zhu \& Simon, 1987), its use as a research tool has not been fully explored. Zazkis and Leikin (2007) explore its use in researching prospective teachers' grasp of number theory. In constructing examples, learners are required to become aware of variant and invariant properties of the examples. Because teachers and learners may be attending to different features of an example, Watson and Mason (2005) extended Marton's notion of "dimensions-of-variation" in examples to "dimensions-of-possible-variation" to highlight the nature of the potential difference in attention between and among teacher and students. According to Watson \& Mason (2005), encouraging learners to generate examples of mathematical objects can expand their example space and shift their attention away from the particularities of examples to generalizations. By prompting learners to construct examples, what they choose to change reveals dimensions, depth and scope of their awareness. Constructing examples forces them to attend to form in the example and disregard details that make up the example. Discerning generality with an awareness of particular details in mathematical examples requires learners to be sensitive to what can change and what must remain constant. Learners need to look at mathematical objects in terms of their structure to discern properties that are structural (invariant) and those that are optional (variant). Example-construction involves certain awareness, on the part of the learner, of what is allowed to change so that the example still maintains its fundamental characteristics. Zaslavsky and Lavie (2005) suggest that "specific elements and representation of an example or set of examples, and the respective focus of attention facilitated by the teacher, have bearing on what learners notice, and consequently, on their mathematical understanding" (p. 2). The use of example construction task in this study serves as sources of evidence of understanding by providing opportunities for learners to reveal their awareness, based on Gattegno's claim that 'only awareness is educable'. By asking learners to construct examples that meet specified constraints, what they choose to change reveals the focus of their attention and aspects of their awareness and understanding. In particular, what learners make of mathematical examples and their awareness of what can vary and what must be kept constant to maintain the exemplary nature of the examples can reveal dimensions and depth of their understanding of the topic.

\section{AIM OF STUDY}

In this study, example construction tasks will be used as a way of revealing aspects of learners' awareness of the concept of Integration as area enclosed between two graphs, namely $f(x)=1-x$ and $f(x)=0$. Because the $x$-axis is essentially $y=0$, I will be referring to the problem investigated as area under the graph. The nature of examples constructed by learners will be investigated. By studying aspects of learners' awareness of dimensions-of-variation as revealed in their examples, I seek to explore the different ways by which learners 
conceptualize Integration as area. The study aims to answer the question "In what ways do examples constructed by learners reveal aspects of their awareness of Integration as area enclosed between graphs?"

\section{METHOD}

Purposive sampling was used to select four students in their first year of undergraduate studies in north England. These students (Denise, Stuart, Marlene and Rick) were invited to construct relevant mathematical examples meeting specified constraints in the topic of Integration. Denise was an education major (Postgraduate Certificate in Education), Stuart was an engineering major, Marlene was an average mathematics major and Rick was an above average mathematics major. The three disciplines were chosen because they would have studied Integration substantially enough to say something about it. The sessions were tape-recorded and later transcribed.

\section{The Task}

The integral of $\int_{0}^{2}(1-x) d x$ gives the answer zero.

Can you find another example like this for which the answer is 0 ?

Can you find another?

And another?

What is the most general example you can think of?

The task was intended to explore whether learners have a sufficiently rich awareness to see an integral as an object and a process at the same time (Gray and Tall, 1994). The intention was to shift learners' attention from the process of integration to integrals as objects and to see whether learners could make this shift. By asking participants to construct another example and another, I hoped to provide opportunity for them to shift their attention from perceiving the object as a particular instance to a representative of a general case. Mason (1989) suggests that to 'abstract' is to 'draw away' and that abstracting is a "delicate shift of attention" when learners draw away from the particular to the general in an "extremely brief moment" (p. 2). This shift of attention is necessary to enable abstraction of aspects that are variant and invariant in the example and to generalise.

Also, the aim was to explore the way in which learners appreciate the shift in attention from the details of the example to what is invariant and thus, structural. Of course, details of examples not mentioned do not mean that they are insignificant, nor does it mean that the person is unaware of them, but only that they were not considered important enough or relevant enough to mention. I concur with both Marton and Booth (1997) and Gattegno (1987) in their observations that experiencing a phenomenon entails back-grounding and foregrounding: stressing certain aspects of the phenomenon and ignoring others.

\section{DATA ANALYSIS}

Responses in the construction tasks ranged from displays of superficial understanding to evidence of considerable sophistication.

\section{Denise}

Denise simply reversed the order in the function and constructed $\int_{0}^{2}(x-1) d x$. In this instance she did not display awareness of other possible dimensions that could be varied.

Denise: $\quad$ It should be $(x-4 x)$. Or you can make it $\int_{0}^{4}\left(x-4 x^{3}\right) d x \ldots$ It won't work. Yeah ... it will work if you do multiples of 4 . If you do $\int_{0}^{5}\left(25-x^{4}\right) d x$ it works. [Checks] $\left(25-\frac{5^{4}}{4}\right)$. No, it has to be another multiple of $5 \ldots 125$.

Researcher: Can you give another example?

Denise: $\quad \int_{0}^{6}\left(6^{4}-x^{5}\right) d x$

In producing a general example for the task, Denise constructed $\int_{-1}^{1} x d x$ and $\int_{-1}^{1}-x d x$, and after checking whether they worked, suggested that making one [limit] negative and one [limit] positive might work. 
Responding to the probe 'What can you change in the example?' Denise suggested that the limits and the expression could change and then added:

Denise: $\quad$ When you change [upper] limits, take multiples of limits. For example 5 [you take] 125.

It seems that Denise was so caught up in the act of finding relationships and generalizing that she overlooked other useful connections to the integral. She did not display any awareness of associations of the integration with area. She appeared to have focused on the process aspect and not to the concept of integration. Her attention needed to be explicitly directed to this aspect for her to associate the integration with area.

\section{Stuart}

Stuart expressed awareness that limits could change when he asked if it had to be the same limits. He displayed awareness that if the limits were kept constant, the function could be varied. He observed that 'if the limit is the same then any function is going to be zero'. He constructed $\int_{-a}^{a} \sin x d x$ and $\int_{0}^{2}(4-4 x) d x$, one after another. Asked to construct another example, he seemed compelled to 'try and think of a good one' and constructed $\int_{0}^{2}\left(x^{2}-\frac{1}{x}\right) d x$.

Stuart: $\quad$ I was going to do that with a different number or may be do a cos or a tan. tan is the same, isn't it? You can substitute the sine with tan and then they're a bit the same.

He then changed it to $\int_{0}^{2}\left(x-\frac{1}{x}\right) d x$. He tried to construct an example that maintained the same limits but with a different function by manipulating it. After trying with $\int_{0}^{2}\left(2 x-\frac{1}{x}\right) d x$, he suggested that the example did not work. In the end, he had to be reminded that the integral of $\frac{1}{x}$ is $\ln x$, which he then recognized. Stuart's attention seemed to fluctuate between algebraic and graphical representation of the integral. The dimensions he varied and the range-of-permissible-change he displayed suggest a richness of connections between technique and associations. He also appeared very articulate in expressing the dimensions he varied but displayed rather limited facility.

Stuart: $\quad$ That one $\int_{0}^{2}(4-4 x) d x$ I just took the constant out because any constant you put in front there is not going to change it. That one $\int_{-a}^{a} \sin x d x$ I thought of the graph and worked it out. And that one $\int_{0}^{2}\left(2 x-\frac{1}{x}\right) d x$, I went all over my head and tried to work it out but it didn't make the job.

Researcher: In what ways are your examples like my example and in what ways are they different?

Stuart: That one is different because it has got a trigonometric function there and because the limits aren't set $\int_{-a}^{a} \sin x d x$. That one is the same because it has the same limit that is different, different coefficient $\int_{0}^{2}(4-4 x) d x$ and that one $\int_{0}^{2}\left(2 x-\frac{1}{x}\right) d x$ is different because it doesn't work [laughs].

Asked to generalize, he constructed $\int_{0}^{2}(a-a x) d x=0, a \int_{0}^{2}(1-x) d x$, representing the coefficient $a$ for the scalar multiplication. He seemed to be dominated by technique manipulation (behaviour to be at the foreground of awareness) and suppressed useful connections that could help to get a sense of it. The fact that no reference was made to area substantiates this claim, apart from the single trigonometric example.

\section{Marlene}

Marlene chose to change the upper limit in the example given.

Marlene: $\quad \int_{0}^{3}(1-x) d x$

Researcher: Can you find another example?

Marlene: I'm suspecting you can change it to whatever you want.

Researcher: Give me one example.

Marlene: $\quad \int_{0}^{4}(1-x) d x$

Researcher: And another?

Marlene: $\quad$ I think 5 will work $\int_{0}^{5}(1-x) d x$. 
Researcher: What is the most general definite integral you can think of for which the answer is 0 ?

Marlene: $\quad \int_{0}^{n}(1-x) d x$

She gave no indication of checking her examples to make sure they were correct. It could be the case that Marlene's attention was focused on the operation (minus) and the answer (zero). Her attention appeared to be shifting between applying rules of integration and plugging in values. With the way Marlene's awareness was structured, it was only natural for her to generalize the integral to $\int_{0}^{n}(1-x) d x$. This can be accounted for by suggesting that her attention was focused on limits and techniques of integration and she was ignoring the connection to area.

Having been probed further to articulate her thinking, she submitted that her examples were not going to work because the second term had squared terms over a number, which did not equal the first term. Marlene's conjecture was that the denominator in the second term would be the same as the new upper limit. Her attention seemed to be shifting between the second term and its integral. The probe to construct another example seemed to have helped her to become aware of this attention shift.

Researcher: So what have you got as the integral?

Marlene: $\quad \int\left(x-\frac{x^{2}}{2}\right) d x \ldots$ I'm thinking 3 is not going to work. It should be 2 on the bottom there not 3 and 4 is not going to work either, that should be 2 not 4 on the bottom. Because I was thinking $x$ cubed $[x 3]$ and then $x$ to the four $[x 4]$ but it doesn't work that way.

She expressed her previous thinking of working out $\int_{0}^{n}(1-x) d x$.

Marlene: Changing the gap, changing the gap between limits should work, shouldn't it? If the function is the same, if it is there we might get it up to this one. If we bring it to 4 , the gap is still 2 . So $\int_{2}^{4}(1-x) d x$. That's not going to work, is it?

[Long pause]

Researcher: What are you trying to do?

Marlene: $\quad$ Try and improve it.

Marlene's attention then shifted to the limits (previous reference to boundaries), namely the difference between the upper and lower limits. However, seeing difference in limits as a critical 'dimension' could be a temporary misconception. She changed the limits but maintained the same function and the same difference in the limits. This awareness of variability of some of the dimensions, while keeping constant some other dimensions, suggests the extent to which she was aware of the degree of freedom in mathematical objects. Self-checking then suggested to her that the example was not going to work. Further prompts suggested that her attention remained focused on changing the limits and checking the answer. I conjectured that her remarks about 'changing the gap' suggested that Marlene may have some awareness of area.

With the intention of revealing whether Marlene was still aware of and can make use of what she said in relation to her associations with the integral sign $\int$, I prompted her with the following probe:

Researcher: You might want to ask yourselves why it is coming to zero.

Marlene: $\quad$ Because there's no area underneath it touching the graph, touching the $x$-axis.

[Long pause]

Marlene: [After sketching] Aaahh .... they're cancelling each other out. Look at that! Nifty! Because part of the area is underneath and it's negative and it cancels out. ... So we can do [change] both limits, couldn't we? So if we take $x$ [equal to] 3 we get $-2 \ldots$ plus 2 , in which case you want 1 minus (-1) which is equal to 2 , because when you integrate and it crosses the $x$ axis, you have to integrate the parts separately because otherwise they cancel each other out because one is negative and one is positive, then area can't be negative as such. So we've simply got the situation here, we've got these little areas, when $x$ is naught we got 1 , naught and -1 and then naught to 2 , if we sum both of them, we are going to get little areas that are going to cancel each other out.

Marlene's attention now appeared to be shifting from focusing on the task as process to object. This delicate shift of attention (Mason, 1989) did not come naturally for Marlene because she seemed to be focusing on one aspect at a time. Although Marlene rehearsed the fact that integration was area under a graph, what she said 
and what she did when faced with construction task did not match. The fact that she did not think in terms of area with what she was doing suggests that this association did not come to mind on this occasion. She could have associated the object with area but did not think about it in this instance. Having been reminded of this awareness, Marlene immediately made good use of it.

Researcher: So you are saying the integral from ...

Marlene: $\quad$ For example $\int_{-3}^{-1}(1-x) d x$.

Researcher: Can you find another example?

Marlene: $\quad \int_{3}^{-1}(1-x) d x$. I guess -2 would work with $\ldots 4, \int_{-2}^{4}(1-x) d x$.

Researcher: Can you give me a general example for which the answer is zero?

Marlene: $\quad \int_{n}^{n+2} \cdots$

Researcher: Is there anything else that you can change?

Marlene: $\quad$ You can change the function; involve any straight line function that cuts through the origin .... It doesn't necessarily have to go through the origin, does it? You have to set the limit from either side of the point where it did go through. Any straight graph would work.

Researcher: Can you give a general form of integral for which the answer would be zero?

Marlene: I'm trying to think. The gaps are getting bigger, so how do we describe that?

Marlene now displayed awareness of area by changing both limits (but maintaining the function). She constructed two more examples by changing both limits simultaneously.

When prompted to reveal her awareness of other dimensions that were variable, she displayed awareness of the function as a variable dimension, although she limited the function to any straight line graph. Although she expressed appreciation of the symmetry in words, she did not reflect that appreciation in the symbolic expression of her general example. For a general example, Marlene did not express symbolically the dimension that was changing (gap between limits). No comment was made about the use of different letters in place of $x$ which was a syntactic rather than semantic dimension-of-possible-variation. What seemed salient for her at this point was the changing of the limits, which was reflected in the general example she constructed in which she was still acting in terms of a difference of 2 rather than the symmetrical orientation of the parts of the area above and below $x$-axis.

\section{Rick}

The construction tasks revealed a different range of Rick's awareness. In Task 1, he first constructed $\int_{0}^{1}\left(\frac{2}{3} x-x^{2}\right) d x$ and remarked that fixing those limits and solving the integral would come out as zero. Constructing subsequent examples, he noted:

Rick: I'm still trying to find the limits .... actually no ... I'll do integral of $\sin x d x$ from $-\pi$ to $\pi$ and work that out by visualizing it pictorially because you know sine graph that goes ... it's an odd function. [...] if you integrate an odd function from $-a$ to $a$ it comes out as zero.

Asked to construct another example, Rick generated a particular odd function $\int_{-a}^{a} x d x$, observing ' $x$ is the simplest odd function'. Although initially he varied the limits and the function, he quickly displayed awareness of the object and generalized. He was somewhat articulate in expressing his ideas. He remarked:

Rick: I've been taken away from that example because to me that looks more difficult that what I'm doing here [referring to his third example] because that has got two numbers to deal with, you've got $1-x$, so you have to think of whether you are evaluating that with the limits. You've got four numbers to think about whereas what I'm doing with the odd function is a lot simpler, easier to think about.

The construction task not only drew out Rick's facility with technique and the robustness of his awareness, it also highlighted his fluency of language. His remarks revealed a good deal more of these aspects of his understanding. His careful disposition and the intensity of his voice tone suggest willingness to engage in and commitment to the tasks and to detecting and experiencing generality. 
Table 1. Summary of examples constructed by participants

\begin{tabular}{ccccc}
\hline & Example 1 & Example 2 & Example 3 & Comments \\
\hline Denise & $\int_{0}^{2}(x-1) d x$ & $\int_{-1}^{1} x d x$ & $\int_{-1}^{1}-x d x$ & $\begin{array}{c}\text { Correct examples but with } \\
\text { minor changes. }\end{array}$ \\
\hline Marlene & $\int_{-a}^{a} \sin x d x$ & $\int_{0}^{2}(4-4 x) d x$ & $\int_{0}^{2}\left(2 x-\frac{1}{x}\right) d x$ & $\begin{array}{c}\text { Correct examples except } \\
\text { third example; structural } \\
\text { awareness of form. }\end{array}$ \\
\hline Rick & $\int_{0}^{3}(1-x) d x$ & $\int_{0}^{4}(1-x) d x$ & $\int_{0}^{n}(1-x) d x$ & $\begin{array}{c}\text { Minor changes; wrong } \\
\text { examples; no structural } \\
\text { awareness of form (only } \\
\text { systematic variation was in } \\
\text { error). }\end{array}$ \\
\hline & $\int_{0}^{1}\left(\frac{2}{3} x-x^{2}\right) d x$ & $\int_{-\pi}^{\pi} \sin x d x$ & $\int_{-a}^{a} x d x$ & $\begin{array}{c}\text { Structural awareness of form } \\
\text { (odd functions). }\end{array}$ \\
\hline
\end{tabular}

\section{SUMMARY OF FINDINGS}

Table 1 presents a summary of examples constructed by the participants in this study. It contains the participants' examples and a brief commentary of each example constructed. Where appropriate, the commentary section of the table includes remarks on whether the participants have displayed awareness of structure in the examples they constructed (variety and scope of dimensions varied, summarized as structural awareness).

From the table we can see that Denise was concerned with manipulating the given example and varying limited dimensions in the example. Her examples were limited to linear functions. Changes made were minor and demonstrated almost no awareness of structure. There was no evidence of thinking in terms of area in the examples she constructed. Stuart, on the other hand, displayed awareness of area. He produced classic familiar examples and displayed awareness of form. Marlene, as Denise, displayed a tendency to manipulate the given example, varying limited dimensions and showing limited awareness of area. Rick displayed awareness of area in the examples he constructed. He varied more dimensions and varied extensively. He produced nonlinear functions and displayed awareness of structure.

\section{CONCLUSION AND DISCUSSION}

The dimensions-of-variation in the examples constructed by the participants in this study provided insight into the scope of their awareness. This in turn could be used to inform the choice of pedagogic strategies to enrich awareness of topics in the future. The construction task provided a way of distinguishing between learners, teaching approaches, and uses for mathematical topics. This was accomplished by providing opportunity for all the subjects in this study to reveal a range of specific and pertinent aspects of their awareness. As such, some of them revealed more depth in their responses than others in the aspects probed.

Example construction tasks could enable teachers to recognise aspects which need strengthening so that learners have a more balanced and informed awareness of topics. In particular, where there is a propensity to stress techniques, teachers can direct attention, through example-construction, to missing elements. Being pushed beyond mere use of techniques to get answers proved to be challenging for participants in this study because of the novelty of the tasks, in which case familiarity with the usual contexts of integration was compromised. However, for some of them, the nature of the tasks themselves afforded a shift in seeing integration in its totality. For others, explicit directing of attention to realise this shift was needed. And for yet others, the dominance of techniques alone prevented them from appreciating such a shift.

Prompting learners to construct examples systematically one after another opened up dimensions-ofpossible-variation in the objects for the learner to discern and vary properties that can be varied. It not only revealed aspects of the object that are focused on, but also revealed their awareness of dimensions-of-possiblevariation and sense of generality. Technique of integration appeared to be the aspect that learners focused on and therefore discerned and varied. Other aspects of the object such as area did not seem to be in the focal of their awareness and therefore not focused on. This aspect needed extra triggers to be discerned or varied. Getting the learning to talk about aspects of the concept that were not previously salient to them reveals the 
dynamics of learners' awareness. The effect of having learners construct mathematical objects provides educators and researchers with an insight into the nature of collaborative efforts and effective partnership that can be afforded with the students and within the educational research community with the common aim of revealing learners' awareness.

\section{Disclosure statement}

No potential conflict of interest was reported by the authors.

\section{Notes on contributors}

Shafia Abdul Rahman - Abu Dhabi University, United Arab Emirates.

\section{REFERENCES}

Abdul Rahman, S. (2005). Learning with Examples and Students' Understanding of Integration. Proceedings of the 8th International Conference of Mathematics Education into the 21st Century Project, Johor Bahru, Malaysia, 24-28.

Bezuidenhout, J., \& Oliver, A. (2000). Students' conceptions of the integral. In T. Nakahara \& M. Koyama (Eds.). Proceedings of the 24th Congress of the International Group for the Psychology of Mathematics Education, 2, 73-80. Hiroshima, Japan.

Czarnocha, B., Dubinsky, E., Loch, S., Prabhu, V., \& Vidakovic, D. (2001). Conceptions of area: In students and in history. The College Mathematics Journal, 32(2), 99-109. https://doi.org/10.2307/2687114

Dahlberg, R., \& Housman, D. (1997). Facilitating learning events through example generation. Educational Studies in Mathematics, 33, 283-299. https://doi.org/10.1023/A:1002999415887

Dreyfus, T., \& Eisenberg, T. (1991). On the reluctance to visualize in mathematics. In W. Zimmermann \& S. Cunningham (Eds.), Visualization in Teaching and Learning Mathematics (pp. 25-37). MAA Notes No. 19.

Gattegno, C. (1987). The Science of Education, Part I: Theoretical Considerations. New York: Educational Solutions.

González-Martín, A.S., Bloch, I., Durand-Guerrier, V. \& Maschietto, M. (2014). Didactic Situations and Didactical Engineering in university Mathematics: Cases from the study of Calculus and Proof. Research in Mathematics Education, 16(2). https://doi.org/10.1080/14794802.2014.918347

Gray, E. M. \& Tall, D. O. (1994). Duality, ambiguity and flexibility: A proceptual view of simple arithmetic. Journal for Research in Mathematics Education, 25(2), 115-141. https://doi.org/10.2307/749505

Griffin, P., \& Gates, P. (1989). Project Mathematics UPDATE: PM753A, B, C, D, Preparing to teach angle, equations, ratio and probability. Milton Keynes, UK: Open University.

Hazzan, O., \& Zazkis, R. (1999). A perspective on "Give an example" tasks as opportunities to construct links among mathematical concepts. FOCUS on Learning Problems in Mathematics, 27 (4), 1-14.

Hong, Y. Y., \& Thomas, M. O. J. (1998). Versatile Understanding of integration, Proceedings of the International Congress of Mathematics Instruction - South East Asian Conference on Mathematics Education, Seoul, Korea, 255-265.

Huang, C. H. (2012). The role of examples in the learning of definite integral. World Transactions on Engineering and Technology Education, 10(4), 236-240.

Jones, S. R. (2013). Understanding the integral: Students' symbolic forms. The Journal of Mathematical Behaviour, 32(2), 122-141. https://doi.org/10.1016/j.jmathb.2012.12.004

Leinhardt, G. (1993). On teaching. In R. Glaser (Ed.), Advances in Instructional Psychology (pp. 1-54). Hillsdale, NJ: Lawrence Erlbaum Associates.

Marton, F., \& Booth, S. (1997). Learning and Awareness. Mahwah, NJ: Erlbaum.

Mason, J. (1989). Mathematical abstraction as the result of a delicate shift of attention. For the Learning of Mathematics, 9 (2), 2-8.

Mason, J., \& Johnston-Wilder, S. (2004a). Designing and using mathematical tasks. Milton Keynes, UK: Open University. (2006 reprint: St. Albans, UK: QED). 
Mason, J., \& Johnston-Wilder, S. (2004b). Fundamental constructs in mathematics education. London: Routledge Falmer.

Orton, A. (1983). Students' understanding of integration. Educational Studies in Mathematics, 14, 1-18. https://doi.org/10.1007/BF00410540

Rasslan, S., \& Tall, D. (2002). Definitions and images for the definite integral concept. In Cockburn A. and Nardi, E. (Eds). Proceedings of the 26th Conference of the International Group for the Psychology of Mathematics Education, Norwich, United Kingdom, 4, 89-96.

Sealey, V. (2006). Definite integrals, Reimann sums, and area under a curve: What is necessary and sufficient? In Alatorre, S., Cortina, J., Sáiz, M. \& Méndez, A. (Eds.), Proceedings of the 28th annual meeting of the North American Chapter of the International Group for the Psychology of Mathematics Education (pp. 46-53). Mérida, México: Universidad Pedagogica Nacional.

Swinyard, C. (2011). Reinventing the formal definition of limit: The case of Amy and Mike. The Journal of Mathematical Behaviour, 30 (2), 93-114. https://doi.org/10.1016/j.jmathb.2011.01.001

Tall, D. (1993). Students' difficulties in calculus. Proceedings of Working Group 3 on Students' Difficulties in Calculus, ICME-7, Québec, Canada, 13-28.

Tall, D., \& Vinner, S. (1981). Concept image and concept definition in mathematics with particular reference to limits and continuity. Educational Studies in Mathematics, 12(2), 151-169. https://doi.org/10.1007/BF00305619

Tsamir, P. (2007). Should more than one theoretical approach be used for analyzing students' errors? The case of areas, volumes and integration. Learn Math, 27(2), 28-33.

Sfard, A. (1994). Reification as a birth of a metaphor. For the Learning of Mathematics, 14(1), 44-55.

Watson, A., \& Mason, J. (2005). Mathematics as a Constructive Activity: The role of learner-generated examples. Mahwah, NJ: Erlbaum.

Weber, K., \& Alcock, L. (2004). Semantic and syntactic proof productions. Educational Studies in Mathematics, 56, 209-234. https://doi.org/10.1023/B:EDUC.0000040410.57253.a1

Zaslavsky, O., \& Lavie, O. (2005). Teachers' use of instructional examples. Proceedings of the $15^{\text {th }}$ ICMI study conference: The Professional Education and Development of Teachers of Mathematics. Águas de Lindóia, Brazil.

Zazkis, R., \& Leikin, R. (2007). Generating examples: From pedagogical tool to a research tool. For the Learning of Mathematics, 27(2), 15-21.

Zazkis, R., \& Leikin, R. (2008). Exemplifying definitions: a case of a square. Educational Studies in Mathematics, 69, 131-148. https://doi.org/10.1007/s10649-008-9131-7

Zhu, S., \& Simon, (1987). Learning mathematics from examples and by doing. Cognition and Instruction, 4, 137-166. https://doi.org/10.1207/s1532690xci0403_1 